\title{
Thiamin Status of the Offspring of Diabetic Rats
}

\author{
MOSHE BERANT, DRORA BERKOVITZ, HANNA MANDEL, OREN ZINDER, AND \\ DANIEL MORDOHOVICH
}

\begin{abstract}
Department of Pediatrics [M.B., D.B., H.M.], Laboratory of Clinical Biochemistry [O.Z.], and Experimental Surgery Unit [D.M.], Rambam Medical Center and Faculty of Medicine, Technion-Israel Institute of Technology, Haifa, Israel
\end{abstract}

\begin{abstract}
Erythrocyte transketolase activity and thiamin pyrophosphate effect were examined in the offspring of streptozotocin-diabetic rats. Thiamin reserve was found to be significantly reduced in litters of untreated diabetic rats as compared to control and to insulin-treated diabetic rats. Supplementation of the untreated diabetic dams throughout pregnancy with oral thiamin was associated with a significantly improved thiamin status of the litters. We conclude that, due to enhanced fetal glucose turnover during diabetic gestation, a fetal thiamin deficiency state may evolve; this condition can be remedied with maternal thiamin supplementation. (Pediatr Res 23: 574-575, 1988)
\end{abstract}

\section{Abbreviations}

RBC-TK, erythrocyte transketolase activity TPP, thiamin pyrophosphate effect

In a normal pregnancy, the fetal thiamin status is independent of maternal status (1). It has been shown to be adequate even in the face of thiamin deficiency in the mother $(1,2)$, thanks apparently to an ability of the fetus to sequester thiamin (3). In a diabetic pregnancy, the fetal thiamin situation is bound to be different. During a diabetic gestation, the intrauterine hyperglycemic milieu may induce fetal hyperinsulinism and acceleration of fetal glucose metabolism (4); the overutilization of thiamin that accompanies accelerated glucose turnover (5) might then lead to fetal/neonatal thiamin deficiency. To our knowledge, this association has not been hitherto studied.

We examined the thiamin status of the offspring of diabetic rats, using RBC-TK assay and the TPP as the expression of thiamin reserve $(6)$.

\section{MATERIALS AND METHODS}

Adult virgin female Sprague-Dawley rats (200-250 g) with normal RBC-TK and TPP were rendered diabetic by an intravenous injection of streptozotocin (Sigma Chemical Co., St. Louis, MO), $35 \mathrm{mg} / 100 \mathrm{~g}$ body weight. Thirty $\mathrm{h}$ after the injection, blood glucose levels ranged between 350 and $460 \mathrm{mg} /$ $\mathrm{dl}$, and there was copious glycosuria. A control group of rats was injected with normal saline (group 1); their blood glucose levels ranged between 68 and $87 \mathrm{mg} / \mathrm{dl}$, and there was no glycosuria. Forty-eight $\mathrm{h}$ after the injection, groups of three rats were placed in cages with a male rat, kept in the dark overnight (1800-0700 $\mathrm{h}$ ), and examined each morning for the presence of a vaginal

Received November 10, 1987; accepted January 29, 1988.

Correspondence Moshe Berant, M.D., Department of Pediatrics B, Rambam Medical Center, P.O.B. 9602, Haifa 31096, Israel.

Supported by Grant 180-750 from the Technion V.P.R. Fund and the Diabetes Research Endowment Fund. plug as evidence of mating having occurred. Mated rats were placed in individual cages. Thirteen of 20 controls and 44 of 100 diabetic rats became pregnant. The diabetic rats were randomly grouped to receive daily a subcutaneous injection of insulin lente (Novo Industri A/S, Copenhagen, Denmark), 1 U (group 2; $n=$ 15 ), or normal saline (group $3 ; n=15$ ). In the insulin-treated rats, blood glucose levels ranged between 86 and $117 \mathrm{mg} / \mathrm{dl}$, and there was only occasional glycosuria. Another group of diabetic rats (group $4 ; n=14$ ) received no antidiabetic treatment, but was given a daily oral thiamin supplement of $5 \mathrm{mg}$. Blood glucose levels were measured every 3 days throughout gestation and were found to range as follows (mg/dl): controls 72-97; insulin-treated diabetics 83-112; and untreated diabetics 196-388. The mean weight over pregnancy increased in the control rats by $33 \pm 2 \%$, in the insulin-treated rats by $34 \pm 1.6 \%$, and in the untreated diabetic rats by $29 \pm 2 \%$, which suggests that they behaved metabolically as "mild diabetics," despite markedly elevated blood glucose measurements.

Six to $8 \mathrm{~h}$ after delivery the pups were decapitated; a pooled sample of blood obtained from the whole litter was examined for glucose and insulin concentrations and assayed for RBC-TK and TPP. Maternal blood was examined for glucose concentration and RBC-TK.

Blood glucose was measured by a glucose oxidase method (ASTRA Analyzer, Beckman Instruments, High Wycombe, Bucks, England). Serum insulin was measured by radioimmunoassay (7). RBC-TK and TPP were determined by the micromethod described by Brin (6). Statistical analysis was performed by Student's $t$ test.

\section{RESULTS}

Number of pups per litter. The mean litter sizes of the control rats (group 1) and of the insulin-treated diabetic rats (group 2) were similar: $9.3 \pm 0.8$ and $8.8 \pm 0.5$ pups, respectively. The mean litter size of the untreated diabetic rats (groups 3 and 4) was significantly smaller: $6.1 \pm 0.2(p<0.05)$.

Litter weight. There was no significant difference between the weights of litters from control rats (group 1) and those from insulin-treated rats (group 2). The mean weight of the offspring of the noninsulin-treated diabetic rats (groups 3 and 4) was significantly greater than that of the other two groups: $8.22 \pm$ 0.49 versus $6.50 \pm 0.53 \mathrm{~g}(p<0.02)$.

Blood glucose. Blood glucose levels in the pups from group 2 were no different from those of the controls. In the litters from groups 3 and 4 , blood glucose levels were significantly lower than in group $2(p<0.05)$; they were also lower than in those of group 1, although the difference did not attain statistical significance $(p=0.058)$.

Serum insulin. Serum insulin concentrations in the litters from groups 3 and 4 were significantly higher $(p<0.02$ and 0.05 , respectively) than in those from groups 1 and 2 . 
Table 1. Biochemical findings in diabetic rats and their offspring (mean $\pm S D$ )

\begin{tabular}{|c|c|c|c|c|c|c|}
\hline \multirow[b]{2}{*}{ Group } & \multicolumn{2}{|c|}{ Blood glucose (mg/dl) } & \multirow{2}{*}{$\begin{array}{c}\begin{array}{c}\text { Serum } \\
\text { insulin } \\
(\mu \mathrm{U} / \mathrm{ml})\end{array} \\
\text { Litter }\end{array}$} & \multicolumn{2}{|c|}{ RBC-TK (U/ml) } & \multirow{2}{*}{$\begin{array}{l}\text { TPP (\%) } \\
\text { Litter }\end{array}$} \\
\hline & Maternal & Litter & & Maternal & Litter & \\
\hline 1. Control $(n=13)$ & $79 \pm 13$ & $67 \pm 11$ & $4.8 \pm 1.3$ & $66.2 \pm 8.0$ & $68.4 \pm 7.6$ & $11 \pm 2$ \\
\hline 2. Diabetic + insulin $\mathrm{Rx}(n=15)$ & $86 \pm 14$ & $72 \pm 8$ & $6.3 \pm 1.8$ & $58.0 \pm 11.1$ & $56.0 \pm 7.1$ & $14 \pm 1$ \\
\hline 3. Diabetic $(n=15)$ & $286 \pm 43$ & $39 \pm 6^{*}$ & $11.2 \pm 2.6 \dagger$ & $55.0 \pm 4.7$ & $32.0 \pm 5.0 \ddagger$ & $26 \pm 3 \ddagger$ \\
\hline 4. Diabetic + thiamine $\mathrm{Rx}(n=14)$ & $279 \pm 65$ & $42 \pm 9^{*}$ & $9.8 \pm 1.7 \dagger$ & $63.0 \pm 10.3$ & $53.9 \pm 10.1$ & $14 \pm 2$ \\
\hline
\end{tabular}

$* p<0.05$ versus group 2 .

$\dagger p<0.05$ versus groups 1 and 2 .

$\ddagger p<0.001$ versus groups 1,2 , and 3 .

Erythrocyte transketolase activity. RBC-TK was similar in the dams of all four groups. RBC-TK of the pups from groups 1 and 2 was similar to that of the dams from all the groups. RBC-TK in the pups from group 3 was significant lower than in the pups from groups 1,2 , and $4(p<0.001)$. In the pups from the diabetic rats that were untreated but supplemented with oral thiamin (group 4), RBC-TK was no different from that of the pups from the controls (group 1) and from the insulin-treated diabetic rats (group 2).

Thiamin pyrophosphate effect. TPP was significantly higher in the litters from group 3 than in those from groups 1, 2, and 4 $(p<0.001)$. TPP in pups from group 4 was no different from that found in pups from groups 1 and 2 .

A histologically normal pancreas was observed in the pups from groups 1 and 2. Beta-cell hyperplasia was found in the pancreatic islets of the pups from groups 3 and 4 . The main biochemical findings are summarized in Table 1.

\section{DISCUSSION}

Thiamin plays a pivotal role in a variety of metabolic processes and is a key participant in carbohydrate metabolism $(5,8)$. The requirements of thiamin are proportional to the rate of carbohydrate metabolism; increase of glucose turnover will enhance the utilization of thiamin (5), which may exhaust thiamin reserves and carry dire consequences (9). Such an association may be operative in the fetus of a diabetic pregnancy.

Herein, we found evidence of a reduced thiamin reserve in the newborn litter of rats with untreated diabetes. Akin to what is observed in infants of diabetic mothers $(4,10)$, these pups had pancreatic $\beta$-cell hyperplasia, significantly higher serum insulin concentrations than the controls, and lowered blood glucose levels $6-8 \mathrm{~h}$ after birth. We also found that, perhaps in association with a reduced litter size, the pups from the diabetic dams were also heavier than their counterparts from the control group and from the insulin-treated group. This constellation is indicative of intrauterine hyperinsulinism and increased glucose turnover. The significantly lower RBC-TK and higher TPP in the offspring of untreated diabetic dams suggest that there had also been a concurrent overuse of thiamin, eventually leading to a state of deficiency. However, untreated diabetic dams that received thiamin supplementation during pregnancy produced offspring with a normal thiamin status.

Deficiency of thiamin may exert a damaging influence, either subtle or outspoken, particularly at critical periods of development. The salient feature of the basically metabolic cardiac involvement in infants of diabetic mothers $(11,12)$ resembles that of infantile beriberi $(13,14)$. It thus becomes tempting to speculate that fetal/neonatal thiamin deficiency might play a role in the "infant of diabetic mother" syndrome. Our findings warrant a clinical study to investigate the thiamin status of mother and infant in pregnancies with poor control.

Acknowledgment. The authors thank Ms. Edith Cohen for technical assistance.

\section{REFERENCES}

1. Tripathy K 1968 Erythrocyte transketolase activity and thiamine transfer across human placenta. Am J Clin Nutr 21:739-742

2. Brin M 1969 Effects of cell age and thiamine on erythrocyte transketolase activity. J Vitaminol 15:338-342

3. Brink C, Esila R, Karvonen MJ, Laamanen A 1959 Transfer of thiamine across the placenta of guinea pig. Acta Physiol Scand 47:375-379

4. Freinkel N 1980 Of pregnancy and progeny. Diabetes 29:1023-1035

5. Ariaey-Nejad MR, Balaghi M, Baker EM 1970 Thiamine metabolism in man. Am J Clin Nutr 23:764-778

6. Brin M 1974 Transketolase. In: Bergmeyer HV (ed) Methods of Enzymatic Analysis, Vol 2, 2nd ed. Academic Press, New York, pp 703-709

7. Hales CN, Randle PH 1963 Immunoassay of insulin with insulin antibody precipitates. Biochem J 88:137-146

8. Moran JR, Greene HL 1979 The B vitamins and vitamin C in human nutrition I. General considerations and "obligatory" B vitamins. Am J Dis Child 133:192-199

9. Knee TL, Nakoda T 1983 Wernicke's encephalopathy induced by tolazolamide. N Engl J Med 309:599-600

10. Cowett R, Schwartz R 1982 The infant of the diabetic mother. Pediatr Clin North Am 29:1213-1231

11. Gotgesell HP, Spear ME, Rosenberg HS 1980 Characterization of the cardiomyopathy in infants of diabetic mothers. Circulation 61:441-450

12. Hallidas HL 1981 Hypertrophic cardiomyopathy in infants of poorly controlled diabetic mothers. Arch Dis Child 56:258-263

13. Burgess RC 1958 Infantile beriberi. Fed Proc 17(suppl 2):39-48

14. Lonsdale D 1975 Thiamine metabolism in disease. CRC Crit Rev Clin Lab Sci $5: 289-313$ 